\title{
Surgical Results of Brainstem Cavernous Malformation Haemorrhage
}

\author{
Ali ARSLAN ${ }^{1}$, Kerem Mazhar OZSOY², Semih Kivanc OLGUNER, Vedat ACIK¹, Ismail ISTEMEN ${ }^{1}$, Baris ARSLAN³, \\ Yurdal GEZERCAN ${ }^{1}$, Ali Ihsan OKTEN ${ }^{1}$
}

${ }^{1}$ Adana City Training and Research Hospital, Department of Neurosurgery, Adana, Turkey

${ }^{2}$ Cukurova University Medical Faculty, Department of Neurosurgery, Adana, Turkey

${ }^{3}$ Adana City Training and Research Hospital, Department of Anesthesiology and Intensive Care, Adana, Turkey

Corresponding author: Ali ARSLAN aliarslan26062006@hotmail.com

\section{ABSTRACT}

AIM: To evaluate surgical treatment options, complications and neurological outcomes of patients with cavernous malformations (CMs) in the pons and medulla oblongata.

MATERIAL and METHODS: We retrospectively evaluated 25 brain stem CMs that we operated between 2009 and 2019 . We operated all cases in the first month with suboccipital retrosigmoid and paramedian approach. The cases were evaluated concerning their demographic characteristics, lesion characteristics, radiological imaging results, surgical approach and neurological status.

RESULTS: Overall, 15 patients had CMs in the pons and 10 in the medulla oblongata. The mean age of the patients was 33.48 years, and the cases included 15 male and 10 female patients. The average modified Rankin Score (mRS) score had a mean of 2.36 and median of 2 at the time of admission (Table I). The mean follow-up period was 4.64 years (1-10 years). In the last follow-up assessment, the average $\mathrm{mRS}$ score was mean $=1.84$ and median $=1$. In addition, $14(56 \%)$ patients recovered, $7(28 \%)$ did not show any changes, $3(12 \%)$ got worse, and $1(4 \%)$ died. In our case series, the admission complaints were cranial nerve paralysis $(24 \%)$ in 6 cases, nausea and vomiting in 1 (4\%) and hemiparesis in 17 (68\%).

CONCLUSION: Experience, correct surgical approach and good knowledge of neuroanatomy are important in brainstem CM haemorrhages. Imaging methods, neuronavigation and neuromonitoring use are essential for patients undergoing surgery. In the presence of all these factors, the prognosis of patients will be better.

KEYWORDS: Brainstem, Cavernomas, Surgery, Bleeding

ABBREVIATIONS: CM: Cavernous malformations, Preop: Preoperative, Postop: Postoperative, MRI: Magnetic Resonance Imaging, DTI: Diffusion Tensor Imaging, M: Men, F: Female, mRS: Modified Rankin scale

\section{INTRODUCTION}

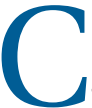
avernous malformations (CMs), gliomas, and hemangioblastomas are common brain stem lesions. Among these lesions, CMs have the highest incidence. CMs have long been considered one of the main pathological categories of vascular malformations of the nervous system
$(4,13,17)$. CMs are included in the definition of cryptic or occult vascular malformations because angiography does not show any abnormal vascularity (22). The term used is cavernous angioma, but more recently the term CM has been more widely recognised, and as expressed by the term angioma, these lesions are clearly distinguished from true vascular neoplasms (16).
Ali ARSLAN (D) : 0000-0002-7457-5283

Kerem Mazhar OZSOY (D) : 0000-0003-4057-2460

Semih Kivanc OLGUNER (D) : 0000-0002-5314-4636
Vedat ACIK (D) : 0000-0002-0371-5883

Ismail ISTEMEN (D) : 0000-0002-2341-4818

Baris ARSLAN (D) : 0000-0001-9386-514X
Yurdal GEZERCAN (D) : 0000-0002-4124-2036 Ali Ihsan OKTEN (D) : 0000-0003-0292-201X 
Brainstem CMs are benign vascular lesions that often present with acute symptoms and have a high morbidity rate. Surgical treatment of these lesions is quite challenging and requires a suitable surgical approach to the brain stem $(3,4,9,10)$. The selection of ideal surgical approach to brain stem CMs according to their anatomical location is a prerequisite for a favorable prognosis. Injury to the critical brainstem structures surrounding CMs lesions can lead to surgery-relatedmorbidity, and therefore, proper operative techniques are very critical in such cases. Appropriate surgical techniques not only resect the lesion but also minimize surgery-related-morbidity and determine the prognosis of the patient after resection. In recent years, there have been great advances in modern surgical methods and imaging, including intraoperative navigation and electrophysiological monitoring, and these advances have further improved the outcomes of brainstem CM surgery $(1,9,10)$.

The present study is intended to evaluate surgical treatments, complications and functional outcomes of patients with CMs in the pons and medulla oblongata.

\section{MATERIAL and METHODS}

Twenty-five patients with CMs in the pons and medulla oblongata were retrospectively evaluated at the Adana City Training and Research Hospital between 2009 and 2019. Preoperative and postoperative MRls and preoperative diffusion spectrum MR tensor imaging (DSI) were performed in all patients. Among patients with clinical signs such as cranial nerve deficit, limb weakness, impaired consciousness or headache, nausea and vomiting, those with MRI showing brainstem haemorrhage were deemed suitable for surgery. Patients with incidentally detected CMs, multiple, CMs without haemorrhage or neurological deficit and deep-located CMs were not included in the study. This study was approved by the ethics board of our hospital (Date: 03.06.220; No: 889). The surgical intervention technique was suboccipital retrosigmoid and median intervention with patients in the sitting position. The patients were neurologically evaluated using the modified ranking scale (mRS) at the time of admission and postoperatively. Our patients underwent operation during the first month.

Neuromonitoring and neuronavigation were used during surgery. The surgical approach was selected according to the location of the brainstem CM, avoiding the cranial nerve nuclei and long path structures, especially when trying to reach the closest point between the pial surface and the lesion. The safe entry zone was determined based on pial presentation, anatomical findings of the brainstem, intraoperative neuronavigation and nucleus mapping. Electrophysiological monitoring of cranial nerves, somatosensory-evoked potentials, motorevoked potentials and brainstem auditory-evoked potentials were routinely performed.

\section{Follow-Up and Statistical Analysis:}

Follow-up data were obtained after retrospectively reviewing the files. The mRS was used to neurologically evaluate each patient during admission, discharge and the latest follow-up.
For logistic regression analysis, the mRS score results were categorised as improving, unchanged and worsening scores based on the differences between the scorings. Multivariate parametric regression models were created. $\mathrm{P}<0.05$ was considered statistically significant. Statistical analysis was performed using IBM SPSS Statistical Package 22.0 version.

\section{RESULTS}

Overall, 15 patients had CMs in the pons and 10 in the medulla oblongata. The mean age of the patients was 33.48 (19-55) years, and the cases included 15 male and 10 female patients. The average modified Ranking Score (mRS) had a mean of 2.36 and median of 2 (Table I), and in the last followup assessment, the average mRS score had a mean of 1.84 and median of 1 . The mean follow-up period was 4.64 (1-10) years. Compared with their preoperative states, 14 patients (56\%) recovered, 7 (28\%) remained unchanged, 3 (12\%) got worse and 1 (4\%) died.

The admission complaints of patients with CMs in the pons (Table I) were hemiparesis and accompanying cranial nerve deficits in 10 patients, cranial nerve VII deficit in 2, cranial nerve VIII deficit in the other 2 and nystagmus in 1 . Total resection of the lesions was achieved in all patients. There were no sudden deaths associated with the surgery (1 year later, 1 patient died due to repeated attacks of pneumonia), and no patient showed bleeding on their postoperative MRI. Histopathological examination of the lesions confirmed the diagnosis of CMs. Based on the difference between $\mathrm{mRS}$ scores during the postoperative period, 3 patients got worse, 4 remained unchanged and 8 recovered in this group of patients.

The admission complaints of the patients with CMs in the medulla oblongata (Table II) were hemiparesis and accompanying cranial nerve deficits in seven patients, cranial nerve XII deficit in one, loss of tactile sensation in one, and nausea and vomiting in one. Total resection of the lesions was achieved in all patients, and there was no postoperative bleeding. Histopathological examination of the lesions confirmed the diagnosis of CMs. Based on the difference between $\mathrm{mRS}$ scores during the postoperative period, 1 patient got worse, 3 remained unchanged and 6 recovered in this group of patients.

Single-sample chi-square analysis showed normal distribution because the distribution of both gender and location showed $p>0.05$.

In the two-way chi-square analysis, there was no significant correlation between gender and location (Fisher exact test, $p>0.05$ ). Because the categorised $m R S$ results and gender showed $p>0.05$, there is no statistical correlation between gender and outcome. Further, because the categorised $\mathrm{mRS}$ results and location showed $p>0.05$, there was no statistical correlation between location and outcome.

The normality test performed to determine if there is a statistically significant difference between the preoperative and postoperative mRS results did not show a normal distribution (Kolmogorov and Shapiro, $\mathrm{p}<0.05$ ). Therefore, the 
Table I: Characteristics of CMs Located in the Pons

\begin{tabular}{|c|c|c|c|c|c|}
\hline Patients & $\begin{array}{l}\text { Location of } \\
\text { CMs in the } \\
\text { pons }\end{array}$ & Preoperative condition & $\begin{array}{l}\text { Preoperative } \\
\text { mRS }\end{array}$ & Postoperative status & $\begin{array}{c}\text { Postoperative } \\
\text { mRS }\end{array}$ \\
\hline 2 & Posterior & $\begin{array}{l}\text { Mild loss of sensation on the left side } \\
\text { of the face }\end{array}$ & 0 & - & 0 \\
\hline 4 & Posterior & Contralateral hemiparesis & 4 & Contralateral subtle hemiparesis & 3 \\
\hline 5 & Posterior & Contralateral subtle hemiparesis & 2 & $\begin{array}{c}\text { Truncal ataxia, left facial } \\
\text { weakness, contralateral } \\
\text { hemiparesis }\end{array}$ & 4 \\
\hline 6 & Posterior & Decreased hearing on the right & 1 & Truncal ataxia & 2 \\
\hline 8 & Posterior & $\begin{array}{l}\text { Contralateral hemiparesis, truncal } \\
\text { ataxia }\end{array}$ & 4 & Contralateral hemiparesis & 3 \\
\hline 9 & Posterior & Contralateral hemiparesis & 4 & Contralateral subtle hemiparesis & 3 \\
\hline 10 & Posterior & Contralateral hemiparesis & 4 & Truncal ataxia & 2 \\
\hline 11 & Anterolateral & $\begin{array}{l}\text { Contralateral loss of tactile sensation } \\
\text { and subtle hemiparesis }\end{array}$ & 3 & $\begin{array}{l}\text { Contralateral loss of tactile } \\
\text { sensation }\end{array}$ & 1 \\
\hline 12 & Anterolateral & Nystagmus, contralateral hemiparesis & 3 & Nystagmus & 1 \\
\hline 13 & Anterolateral & $\begin{array}{l}\text { Ipsilateral hemifacial weakness, } \\
\text { contralateral subtle hemiparesis }\end{array}$ & 3 & Ipsilateral hemifacial weakness & 1 \\
\hline
\end{tabular}

mRS: Modified Rankin scale.

Wilcoxon signed rank test was performed as a non-parametric test. Because the $\mathrm{p}$ value was below 0.05 , the difference between each measurement was significant, and patients were surgically treated.

Because the omnibus test of gender, location and categorised age, which are independent variables in binary logistics regression analysis, showed $\mathrm{p}>0.05$, any model for prediction of recovery could not be created, i.e. there was no correlation between the dependent variable (good outcome) and independent variables.

\section{DISCUSSION}

The present study includes only patients with haemorrhaging brainstem CMs. Patients with incidentally detected CMs, CMs without haemorrhage or neurological deficit and deep-located CMs were not included in the study. The 25 patients included in the study were aged 18 years and above. Paediatric CMs at the age of 18 years and below were considered a separate subject of study. This study presents the demographic structure, preoperative and postoperative neurological status, preoperative $\mathrm{MRI}$ and DSI, intraoperative navigation and neuromonitoring of these surgically treated patients.

In the follow-up cases with incidentally detected brainstem CM haemorrhages, the probability of bleeding was $0.7 \%(24)$. However, after the initial bleeding, the incidence of rebleeding is reported to be $20 \%-60 \%(4,5,12,20)$ each year and the incidence of rebleeding within 1 year after the first reported bleeding is $8 \%$ (5). Recurrent bleeding can exacerbate existing neurological problems. Moreover, it may increase the difficulty of surgical resection and cause more damage to the surrounding tissues of CMs during surgical resection $(8,12)$. Despite these circumstances, CM surgery can aggravate existing neurological deficits or cause new deficits. Most new symptoms are temporary and recover postoperatively. Surgical treatment leads to relatively low mortality and morbidity rates (18). In a study conducted with an 8-year follow-up of patients with brainstem CMs, it was found that patients who underwent conservative treatment had worse prognosis than those who underwent microsurgical resection (12). The cases included 
Table II: Characteristics of cavernous malformations (CMs) Located in the Medulla Oblongata

\begin{tabular}{|c|c|c|c|c|c|}
\hline Patients & $\begin{array}{l}\text { Location } \\
\text { of CMs in } \\
\text { the medulla } \\
\text { oblongata }\end{array}$ & Preoperative condition & $\begin{array}{l}\text { Preoperative } \\
\text { mRS }\end{array}$ & Postoperative status & $\begin{array}{l}\text { Postoperative } \\
\text { mRS }\end{array}$ \\
\hline 1 & Posterior & Nausea, a feeling of vomiting & 0 & $\begin{array}{l}\text { Loss of tactile sensation on } \\
\text { ipsilateral lower extremity }\end{array}$ & 0 \\
\hline 2 & Posterior & $\begin{array}{l}\text { Loss of tactile sensation on ipsilateral } \\
\text { upper extremity }\end{array}$ & 1 & - & 0 \\
\hline 3 & Anterolateral & Ipsilateral weakness in tongue & 0 & $\begin{array}{c}\text { Tracheostomy, quadriparesis, } \\
\text { respiratory distress }\end{array}$ & 5 \\
\hline 4 & Posterior & Subtle hemiparetic on the left & 2 & Subtle hemiparetic on the left & 2 \\
\hline 5 & Posterior & $\begin{array}{l}\text { Subtle hemiparetic on the right, } \\
\text { sensation loss in the right lower limb }\end{array}$ & 2 & $\begin{array}{l}\text { Loss of feeling in the right lower } \\
\text { extremity }\end{array}$ & 0 \\
\hline 8 & Posterior & Left ciliated hemiparesis & 3 & $\begin{array}{l}\text { Ipsilateral loss of sensation in } \\
\text { upper and lower extremities }\end{array}$ & 1 \\
\hline 9 & Anterolateral & $\begin{array}{l}\text { Subtle hemiparetic on the left, } \\
\text { sensation loss in the left upper limb }\end{array}$ & 2 & $\begin{array}{l}\text { Loss of sensation in the left upper } \\
\text { limbs }\end{array}$ & 1 \\
\hline 10 & Anterolateral & $\begin{array}{c}\text { Decreased gag reflex, hemiparesis on } \\
\text { the left }\end{array}$ & 4 & $\begin{array}{l}\text { Decreased gag reflex, weakness } \\
\text { in the tongue muscles on the left }\end{array}$ & 2 \\
\hline
\end{tabular}

mRS: Modified Rankin scale.
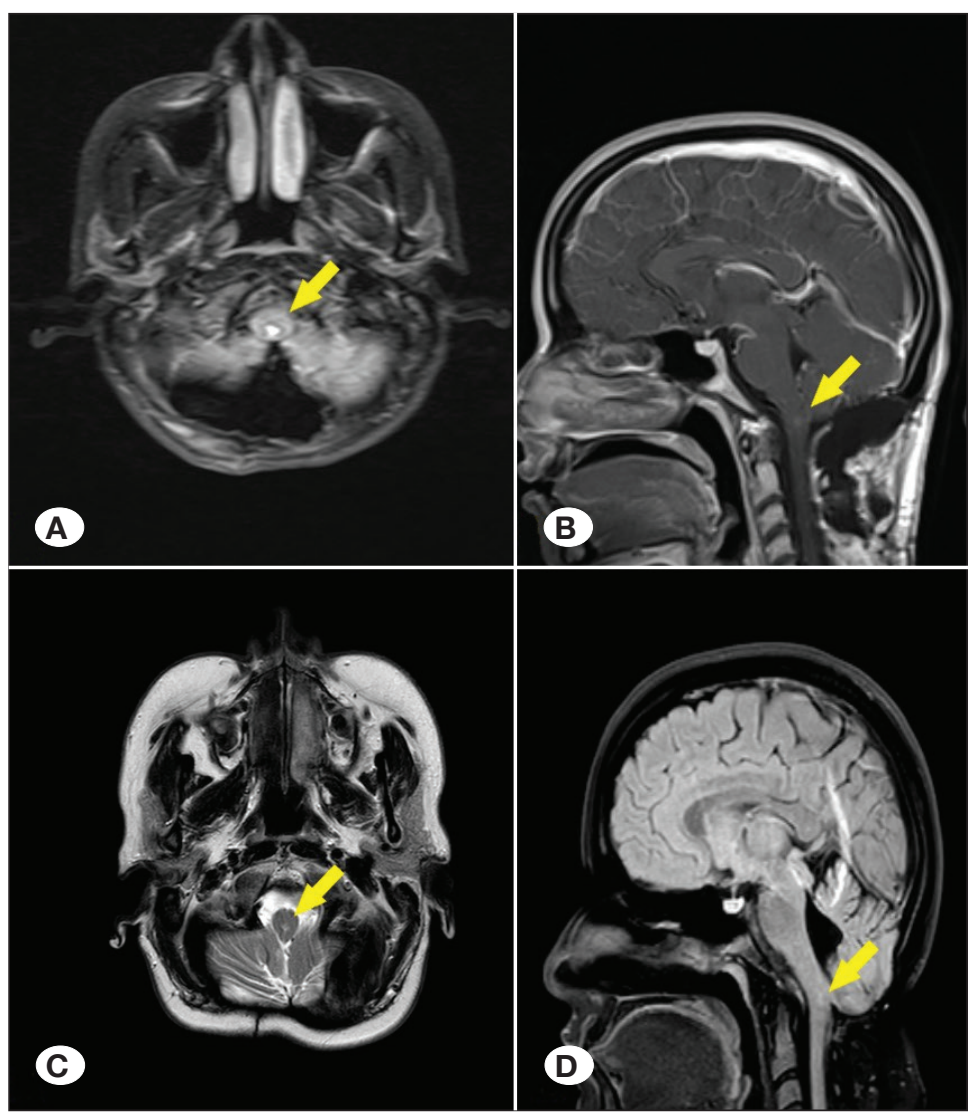

Figure 1: Cavernomas in the medulla oblangata.

A) T2W-Dark fluid axial and B) T1W-contrast enhanced sagittal magnetic resonance imagings (MRIs) of the patient before the operation.

C) T2W axial and D) T1W-contrast enhanced sagittal MRIs follow-up magnetic resonance imagings at 1 year postoperatively. Yellow arrows indicate the lesion area. 

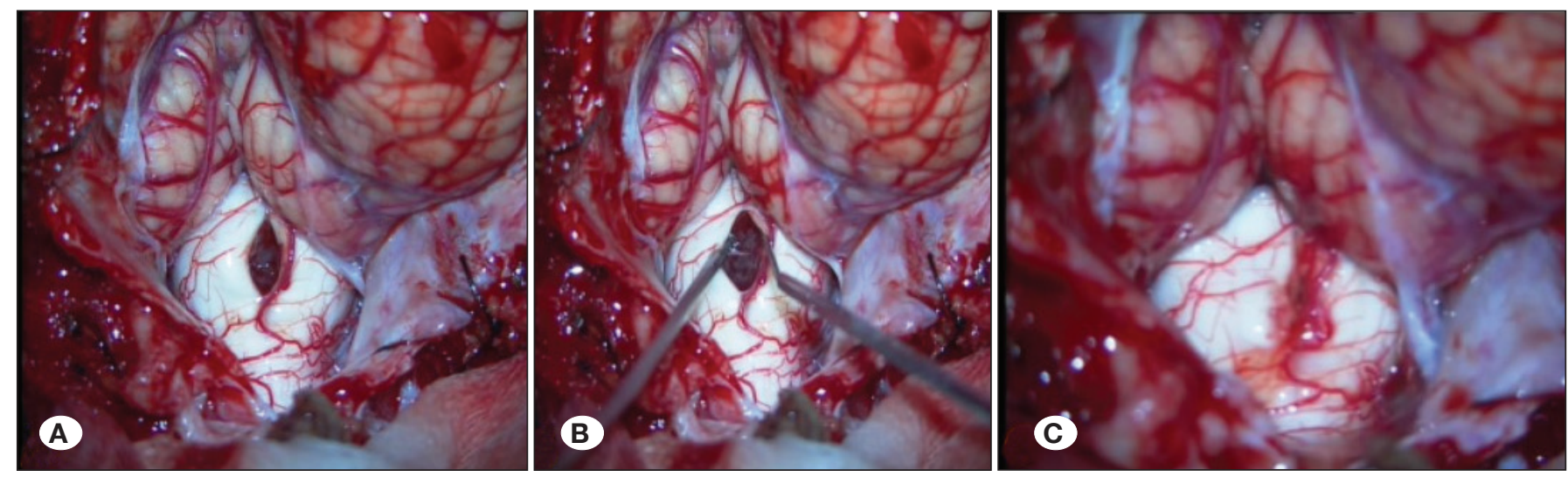

Figure 2: Images taken during the operation of the patient shown in Figure 1. A) Cavernoma located in the medulla oblongata. B) Surgical dissection and removal of cavernoma. C) Surgical photomicrograph after successful cavernoma excision.
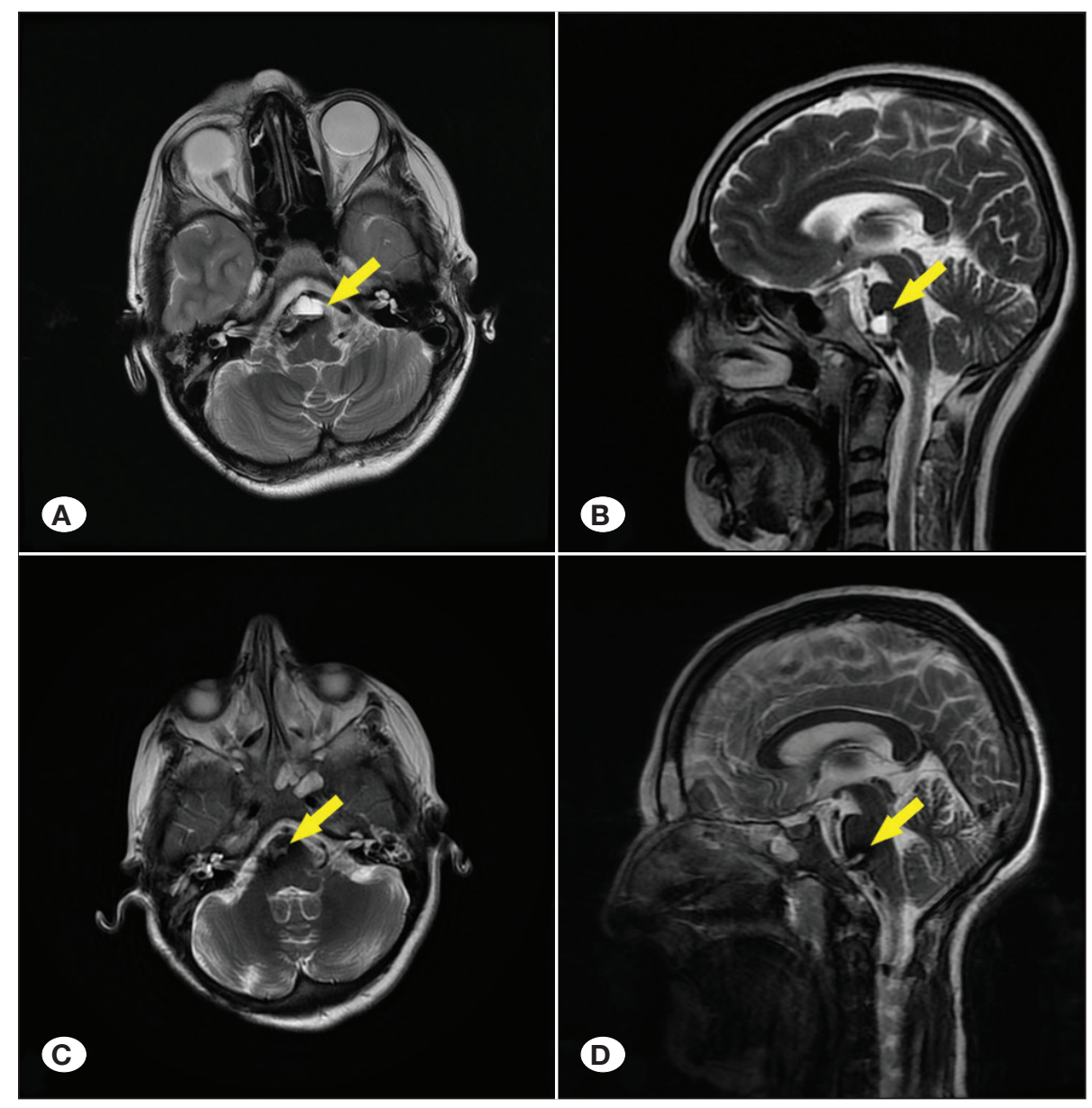

Figure 3: Lesions in the anterior pons. Preoperative T2W axial (A) and sagittal (B) magnetic resonance imagings (MRIs). Postoperative T2W-FSE axial (C) and sagittal (D) MRIs. Yellow arrows indicate the lesion area.

in the present study had brainstem CM haemorrhages and clinically presented with neurological symptoms; therefore, in appropriate cases, surgery was preferred over follow-up due to the high probability of rebleeding mentioned above.

\section{CMs Located in the Pons}

In 10 of the 15 patients with CMs located in the pons, CMs were found in the posterior region, and preoperative MRI revealed that eight of these were associated with the rhomboid fossa. The technique of surgical intervention in these patients was suboccipital median incision with patients in the sitting position. After occipital craniotomy, the posterior arch of C1 was taken so that the pontomesencephalic junction could be more easily observed. Telovelar transcerebellar approach was used for access. In these patients, we added transvermian interference because the CMs in eight patients was close to 
the pontomesencephalic junction. Although the transvermian intervention is not recommended in the literature $(6,21)$, we used this approach to provide better visibility during the surgery. In these patients, there was bleeding in the rhomboid fossa in the suprafacial triangle, which showed CM in the pial region under a microscope. CMs in the eight patients were removed by entering this detected bleeding area. CMs in two patients were located in the central part of the rhomboid fossa. In these patients, the transvermian approach was not needed for entry. They showed no pial connection but were not deep located. In the infrafacial triangle considered based on neuronavigation and anatomical landmarks, stimulus was given using neuromonitoring. After the facial and hypoglossal parts were detected, they were entered through the infrafacial triangle on the left side located between them. The CMs located below the surface were excised. CMs in five patients were located in the anterolateral region of the pons. In the preoperative $\mathrm{MRI}$, three patients showed pial connections, of which 2 were slightly deeper. In these patients, suboccipital paramedian retrosigmoid incision was used for entering while patients were in the sitting position. Transverse and sigmoid sinuses were observed. Especially in these cases, we removed more of the mastoid bone and slightly mobilised the sigmoid sinus to achieve visibility of the operating site.
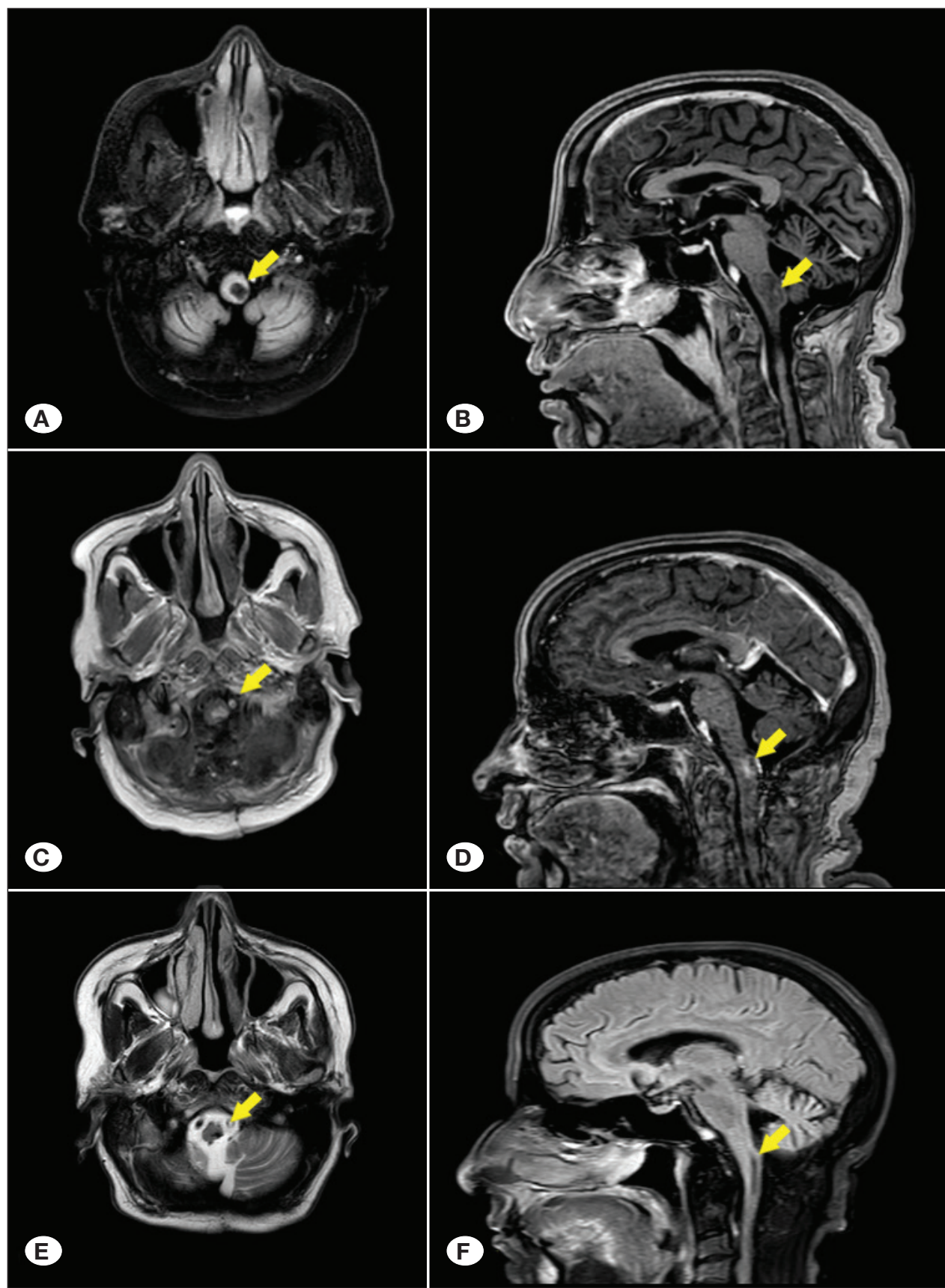

Figure 4: Lesions in the medulla oblongata. Preoperative T2W-Flair axial (A), and sagittal (B) magnetic resonance imagings (MRIs). Followup T1W-contrast enhanced axial (C), and sagittal (D) MRIs at 1 year postoperatively. Follow-up T2WFlair axial (E), and sagittal (F) MRIs at 2 years postoperatively. Yellow arrows indicate the lesion area. 
Entry was made through the lateral part of the cerebellum. As the standard procedure, CMs were removed through the peritrigeminal field, the safe zone between the cranial nerves $\mathrm{V}$ and VII. The presence of bleeding in the pial area during this procedure helped us in 3 patients, whereas in 2 other patients, $\mathrm{CMs}$ were excised by entering through the anatomical landmarks of cranial nerves $\mathrm{V}$ and VII under the guidance of neuromonitoring and neuronavigation. All CM excisions were performed in total.

One of the complications introduced by us during pons surgery was transvermian intervention. This was done to expand the surgical site. Three patients developed postoperative truncal ataxia. This complication did not improve in the patients. Five patients did not develop truncal ataxia.

Preoperative admission examination and postoperative final status of the 15 cases with CMs located in the pons is shown in Table I.

\section{CMs Located in the Medulla Oblongata}

Dorsal CMs were observed in 7 patients, and preoperative $\mathrm{MRI}$ showed that they were all connected to the pial region. Because this area anatomically occupies little space in volume, haemorrhaging CMs usually appear to have a pial connection. As the surgical intervention technique in these patients, a suboccipital median incision was made with patients in the sitting position. The dura was exposed through occipital craniotomy and by taking the posterior arch of $\mathrm{C} 1$. In all cases, pial-affiliated haemorrhage was observed on the posterior median sulcus in the medulla oblongata. Surgically, we removed it within the bleeding capsule, gently touching the surrounding tissues without much traction. Three cases were anteromedially located. In these cases, exposing was done in the same way again. After adjusting the microscope to the surgical site from the lateral area, we achieved visibility of the nerves 9, 10 and 11 as well as an olivary bump structure in the anterior, and the nerve 12 exiting behind it was observed. Pial haemorrhage was observed on the nerve 12 and in the zone of the olivary bump structure. In 2 patients, CMs were smoothly excised by entering the area of the olivary zone from the bleeding spot, without pushing the surrounding tissues. In the third case, there was bleeding and swelling of the tissues while removing the CMs. The bleeding from the base was stopped by re-entering the operated area. This patient showed bad postoperative neurological outcome. Quadriparesis developed and the patient was followed up on ventilator due to respiratory distress. Subsequently, tracheostomy was performed and the patient was sent for physical rehabilitation in a bed-dependent state.

By determining the position of the motor and sensory fibres in the area of CMs using DSI, we determined safe entry zones especially to the deep-located CMs preoperatively. Neuronavigation and neuromonitoring were also helpful during surgery. In the study by Jacop et al., DSI is reported to help enter the safe entry zones for surgical treatment of CMs and achieve good postoperative neurological outcomes in patients $(7,15)$.
The presence of sensitive neurological structures located in the localisation of brainstem CMs renders its surgery very difficult. CMs detected by autopsies and then by MRI have been studied for a long time throughout history. Their natural course and indications for surgery have been investigated (16). Alternative to surgery, gamma knife is performed in these cases in surgery $(11,14)$. It is effective in reducing recurrent bleeding rates. However, there may be complications due to symptomatic radiation and these patients are not definitive treatment.

Surgical outcomes are related to the preoperative condition of the patient. Most authors described surgical outcomes based on the preoperative condition of the patients. Zimmerman et al. reported a mortality rate of $6.3 \%$ and 1 out of 16 patients died (23). In a series of 137 patients, Wang et al. reported a mortality rate of $27.7 \%$ (20). De Aguiar et al. reported morbidity and mortality rates of $15.3 \%$ and $7.6 \%$, respectively (2). Longterm morbidity and mortality rates reported by Steinberg et al. were $5 \%$ and $0 \%$, respectively (19). In the current study, 1 patient (4\%) died during the 12th month due to recurrent attacks of pneumonia in the postoperative period. Based on the patients' preoperative state, 14 patients (56\%) recovered, 7 (28\%) remained unchanged, and 4 (12\%) got worse. According to the bilateral logistics model that we created, categorised age, gender and CM location were not predictive of clinical outcomes.

In a series involving 13 cases, De Aguiar et al. reported that the admission complaints were cranial nerve paralysis (7 and 8 ) in $92 \%$ of the patients, hemiparesis in $7 \%$ and headache in $7 \%$. Only one patient recovered from cranial nerve paralysis in the postoperative period (2). In a study involving 36 cases by Samii et al., it was reported that $72 \%$ of the patients had cranial nerve paralysis, $36 \%$ had motor paralysis and $47 \%$ had sensory loss (18). In our study, 6 patients had cranial nerve paralysis (24\%), 1 had nausea and vomiting (4\%) and 17 had hemiparesis (68\%).

\section{Limitations}

The small number of cases included herein was particularly restrictive in statistical terms. There was no correlation between the preoperative condition of the patients and the outcome. Another limitation was that the follow-up period was not long.

\section{CONCLUSION}

In our study, the patients exhibited low morbidity and mortality owing to surgical experience and selection of the correct surgical corridors based on anatomical location. However, despite our increasing knowledge on the natural course of brainstem CMs and surgical approaches, no treatment algorithm has been developed yet. Further studies should be conducted on the existing and novel treatment approaches. 


\section{REFERENCES}

1. Chen LH, Zhang HT, Chen L, Liu LX, Xu RX: Minimally invasive resection of brainstem cavernous malformations: Surgical approaches and clinical experiences with 38 patients. Clin Neurol Neurosurg 116:72-79, 2014

2. De Aguiar PHP, Zicarelli CAM, Isolan G, Antunes A, Aires R, Georgeto SM, Tahara A, Haddad F: Brainstem cavernomas: A surgical challenge. Einstein (Sao Paulo) 10:67-73, 2012

3. Fritschi JA, Reulen HJ, Spetzler RF, Zabramski JM: Cavernous malformations of the brain stem. A review of 139 cases. Acta Neurochir (Wien) 130:35-46, 1994

4. Gui S, Meng G, Xiao X, Wu Z, Zhang J: Surgical management of brainstem cavernous malformation: Report of 67 patients. World Neurosurgery 122:e1162-e1171, 2019

5. Hauck EF, Barnett SL, White JA, Samson D: Symptomatic brainstem cavernomas. Neurosurgery 64:61-70; discussion 70-71, 2009

6. Heffez DS, Zinreich SJ, Long DM: Surgical resection of intrinsic brain stem lesions: An overview. Neurosurgery 27:789-797; discussion 797-798, 1990

7. Januszewski J, Albert L, Black K, Dehdashti AR: The usefulness of diffusion tensor imaging and tractography in surgery of brainstem cavernous malformations. World Neurosurg 93:377-388, 2016

8. Kearns KN, Chen CJ, Tvrdik P, Park MS, Kalani MYS: Outcomes of surgery for brainstem cavernous malformations: A systematic review. Stroke 50:2964-2966, 2019

9. Li D, Hao SY, Tang J, Xiao XR, Jia GJ, Wu Z, Zhang LW, Zhang JT: Surgical management of pediatric brainstem cavernous malformations. J Neurosurg Pediatr 13:484-502, 2014

10. Li D, Yang Y, Hao SY, Wang L, Tang J, Xiao XR, Zhou H, Jia GJ, Wu Z, Zhang LW, Zhang JT: Hemorrhage risk, surgical management, and functional outcome of brainstem cavernous malformations. J Neurosurg 119:996-1008, 2013

11. Lee CC, Pan DHC, Chung WY, Liu KD, Yang HC, Wu HM, Guo WY, Shih YH: Brainstem cavernous malformations: The role of Gamma Knife surgery. J Neurosurg 117 Suppl:164-169, 2012

12. Mathiesen T, Edner G, Kihlström L: Deep and brainstem cavernomas: A consecutive 8-year series. J Neurosurg 99:3137,2003
13. McCormick WF: The pathology of vascular ("arteriovenous") malformations. J Neurosurg 24:807-816, 1966

14. Park K, Kim JW, Chung HT, Paek SH, Kim DG: Long-term outcome of gamma knife radiosurgery for symptomatic brainstem cavernous malformation. World Neurosurg 116: e1054-e1059, 2018

15. Porter RW, Detwiler PW, Spetzler RF, Lawton MT, Baskin JJ, Derksen PT, Zabramski JM: Cavernous malformations of the brainstem: Experience with 100 patients. J Neurosurg 90:5058, 1999

16. Pozzati E, Marliani AF, Zucchelli M, Foschini MP, Dall'Olio M, Lanzino G: The neurovascular triad: Mixed cavernous, capillary, and venous malformations of the brainstem. J Neurosurg 107:1113-1119, 2007

17. Rigamonti D, Hadley MN, Drayer BP, Johnson PC, HoenigRigamonti K, Knight JT, Spetzler RF: Cerebral cavernous malformations. Incidence and familial occurrence. N Engl J Med 319: 343-347, 1988

18. Samii M, Eghbal R, Carvalho GA, Matthies C: Surgical management of brainstem cavernomas. J Neurosurg 95:825832, 2001

19. Steinberg GK, Chang SD, Gewirtz RJ, Lopez JR: Microsurgical resection of brainstem, thalamic, and basal ganglia angiographically occult vascular malformations. Neurosurgery 46:260-270; discussion 270-271, 2000

20. Wang C, Liu A, Zhang J, Sun B, Zhao Y: Surgical management of brain-stem cavernous malformations: Report of 137 cases. Surg Neurol 59:444-454; discussion 454, 2003

21. Weil SM, Tew JM: Surgical management of brain stem vascular malformations. Acta Neurochir (Wien) 105:14-23, 1990

22. Wilkins RH: Natural history of intracranial vascular malformations: A review. Neurosurgery 16:421-430, 1985

23. Zimmerman RS, Spetzler RF, Lee KS, Zabramski JM, Hargraves RW: Cavernous malformations of the brain stem. J Neurosurg 75:32-39, 1991

24. Ziyal IM, Sekhar LN, Salas E, Sen C: Surgical management of cavernous malformations of the brain stem. $\mathrm{Br} \mathrm{J}$ Neurosurg 13: 366-375, 1999 